\title{
TLR ligands and antigen need to be coencapsulated into the same biodegradable microsphere for the generation of potent cytotoxic $T$ lymphocyte responses
}

\author{
Eva Schlosser ${ }^{a}$, Marc Mueller ${ }^{a}$, Stefan Fischer ${ }^{b}$, Sameh Basta ${ }^{c}$, \\ Dirk H. Busch ${ }^{\text {d,e }}$, Bruno Gander ${ }^{b}$, Marcus Groettrup ${ }^{a, f, *}$
}

a Division of Immunology, Department of Biology, D-78457 Konstanz, Germany

b Institute of Pharmaceutical Sciences, ETH Zürich, CH-8093 Zürich, Switzerland

c Department of Microbiology \& Immunology, Queen's University, Kingston, K7L 3N6 Canada

d Institute for Medical Microbiology, Immunology, and Hygiene, Technical University Munich, 81675 Munich, Germany

e Clinical Cooperation Group Immune Monitoring GSF National, GSF Institute of Health and Environment/Neuherberg and

Technical University Munich, Munich, Germany

f Biotechnology Institute Thurgau, $\mathrm{CH}-8274$ Tägerwilen, Switzerland

\section{KEYWORDS}

Biodegradable microspheres; Viral infection; Cytotoxic T cells

\begin{abstract}
Summary Dendritic cells phagocytose pathogens leading to maturation and crosspresentation on MHC class I. We found that the efficiency of cross-priming in mice after vaccination with biodegradable poly(D,L-lactide-co-glycolide) microspheres (MSs) was enhanced when ovalbumin was coencapsulated together with either a CpG oligonucleotide or polyl:C as compared to co-inoculation of ovalbumin-bearing MS with soluble or separately encapsulated adjuvants. A single immunization with MS containing coencaspsulated $\mathrm{CpG}$ and ovalbumin yielded $9 \%$ SIINFEKL/H-2K ${ }^{b}$ tetramer positive CTLs, production of IFN- $\gamma$, efficient cytolysis, and protection from vaccinia virus infection. Taken together, coencapsulation of adjuvant and antigen is an important paradigm for the generation of potent CTL responses.
\end{abstract}

\footnotetext{
Abbreviations: BMDC, bone marrow-derived dendritic cells; DCs, dendritic cells; MS, microspheres; OVA, ovalbumin; PAMP, pathogenassociated molecular pattern; PLGA, poly(D,L-lactide-co-glycolide).

* Corresponding author at: Lehrstuhl Immunologie, Universität Konstanz, Universitätsstrasse 10, D-78457 Konstanz, Germany.

Tel.: +49 7531 882130; fax: +49 7531883102.

E-mail address: Marcus.Groettrup@uni-konstanz.de (M. Groettrup).
} 


\section{Introduction}

Dendritic cells (DCs) function as master switches that control whether the consequence of antigen encounter is tolerance induction or the stimulation of a cellular immune response [1]. In their immature state, DC reside in peripheral tissues to "sample"' the environment by pinocytosis or phagocytic uptake of pathogens. The consequence of engulfing bacterial or viral particles and their disassembly in phagosomes are twofold. On the one hand antigenic peptides are generated and delivered to MHC class I and II molecules, on the other hand DC receive a maturation signal via TLRs which are stimulated by pathogen-associated molecular pattern (PAMP) molecules [2]. Mature DC then migrate to secondary lymphoid organs, where the acquired material is either presented directly on MHC class II molecules, thus triggering $T$ cell help, or cross-presented to $\mathrm{CD}^{+} \mathrm{T}$ cells on MHC-I [3-5]. In this way all systemically and peripherally expressed antigens can be presented to $T$ cells. Nevertheless, this mechanism implies that self-antigens are presented on dendritic cells, which potentially leads to activation of silent autoreactive $T$ cells finally leading to autoimmunity [6]. To prevent this, dendritic cells only get "licensed" to induce activation of $T$ cells in the presence of TLR ligation.

Recently, Blander and Medzhitov [7,8] have addressed the question how it can be avoided that DC that simultaneously pick up self-antigens and pathogens activate self-reactive T cells. They found that only those phagosomes contributed effectively to presentation on MHC class II molecules in vitro which had endocytosed particulate cargo that contained both the TLR4 ligand LPS and the model antigen ovalbumin. Moreover, it was recently shown that the $T$ helper response to the TLR11 ligand profilin from the parasite Toxoplasma gondii relied on TLR signal transduction by DCs suggesting that the physical association of TLR ligand and antigen is relevant in vivo [9]. These results have important consequences for the design of microparticulate vaccines especially if they can be extended to cross-priming of CTLs.

We and others have explored biodegradable microspheres (MSs) composed of poly(D,L-lactide-co-glycolide) (PLGA) as antigen delivery devices for macrophages and dendritic cells [10]. PLGA-MS of about $0.5-5 \mu \mathrm{m}$ in diameter are actively phagocytosed by human and murine $D C$ and can be used for the encapsulation of DNA, RNA, peptides or proteins. The PLGA polymer hydrolyzes slowly in aqueous environments [11], and releases encapsulated peptides and proteins into the processing pathways for presentation on MHC class I and II [12-14]. While pivotal biological properties of DC like cytokine secretion, migration, and $T$ cell stimulation were not altered by the uptake of PLGA-MS, it became also evident that PLGA-MS by themselves do not trigger the maturation of $D C$ [15]. However, the differentiation of immature human DC that had phagocytosed PLGA-MS occurred normally upon subsequent stimulation with TLR ligand or proinflammatory cytokines.

The overall goal of our work is the optimization of the parameters for subcutaneous vaccination with PLGA-MS for the generation of antigen-specific CTL responses in vivo. In this study, we first realized that the effect of polyl: $\mathrm{C}$ and $\mathrm{CpG}$ oligonucleotides was more prominent when these adjuvants were coinjected in microencapsulated rather than soluble form. Even better results, however, were consistently achieved when antigen and adjuvant were not separately microencapsulated in different MS and coinjected but when they were coencapsulated into the same microparticles. This procedure yielded unprecedented potent CTL responses upon a single injection and demonstrates that the principle described by Blander and Medzhitov for class II presentation in vitro can be extended to cross-priming of $\mathrm{CD}^{+} \mathrm{T}$ cells in vivo.

\section{Materials and methods}

\section{Preparation of microspheres (MS)}

MS were prepared from 14 kDa PLGA 50:50 carrying hydroxyland carboxyl-end groups (Resomer RG502H, Boehringer Ingelheim, Ingelheim, Germany). The antigens and TLR ligands were microencapsulated by spray drying as described elsewhere [16]. Briefly, ovalbumin (Grade V, Sigma) and/or CpG oligonucleotide with a phosphothioate backbone (1826, Microsynth, Balgach, Switzerland) and/or polyl:C (Calbiochem, VWR, Dietikon, Switzerland) were dissolved in $0.5 \mathrm{ml}$ aqueous medium (aqueous phase) and mixed with $1 \mathrm{~g}$ of PLGA dissolved in $20 \mathrm{ml}$ of either dichloromethane or ethyl acetate (organic phase). For individual microencapsulation of OVA, CpG or polyl:C, $50 \mathrm{mg}$ ovalbumin were dissolved in $0.5 \mathrm{ml} \mathrm{H}_{2} \mathrm{O}$ and $1 \mathrm{~g}$ PLGA in $20 \mathrm{ml}$ dichloromethane, or $5 \mathrm{mg}$ of $\mathrm{CpG}$ or polyl: $\mathrm{C}$ were dissolved in $0.5 \mathrm{ml} 0.1 \mathrm{M} \mathrm{NaHCO}_{3}$ and $1 \mathrm{~g}$ PLGA in $20 \mathrm{ml}$ ethyl formate. Coencapsulation of OVA with either of the two adjuvants was performed by co-dissolving $50 \mathrm{mg}$ OVA and $5 \mathrm{mg}$ adjuvant in $0.5 \mathrm{ml}$ of $0.1 \mathrm{M} \mathrm{NaHCO}_{3}$ and $1 \mathrm{~g}$ PLGA in $20 \mathrm{ml}$ dichloromethane. The aqueous and organic phases were homogenized under ultrasonication (Hielscher, UP200 H, Ampl. 40\%) for $10 \mathrm{~s}$ on ice. The obtained w/odispersion was spray-dried (Mini Spray-Dryer 191, Büchi, $\mathrm{CH}$-Flawil) at a flow rate of $2 \mathrm{ml} / \mathrm{min}$ and inlet/outlet temperatures of $40 / 37^{\circ} \mathrm{C}$. The obtained MS were washed out of the spray-dryer's cyclone with $0.1 \%$ poloxamer 188 (Pluronic ${ }^{\circledR} \mathrm{F} 68, \mathrm{BASF}$ ), collected on a cellulose acetate membrane filter and dried under reduced pressure $(20 \mathrm{mbar})$ for $18 \mathrm{~h}$. Before use, indicated amounts of MS were dispersed in indicated aqueous media by ultrasonication for $1 \mathrm{~min}$ in order to obtain a homogenous MS suspension.

\section{Release of antigen and TLR ligands from MS}

Amounts of $10 \mathrm{mg}$ of MS, accurately weighed, were suspended in $1 \mathrm{ml}$ phosphate buffered saline (PBS; pH 7.4) and kept at $37^{\circ} \mathrm{C}$ under mild rotational movement. After 3 days of incubation, the MS suspension was centrifuged, and the supernatant analysed for OVA and CpG. The OVA was assayed fluorimetrically $\left(\lambda_{\mathrm{ex}} / \lambda_{\mathrm{em}}=280 / 334 \mathrm{~nm}\right.$; slits: $10 \mathrm{~nm}$; Cary Eclipse, Varian Optical Spectroscopy Instruments, Mulgrave, Victoria, Australia), and the CpG with the Quant-iT ${ }^{T M}$ Oligreen ${ }^{\circledR}$ ssDNA reagent (Invitrogen/Molecular Probes, Eugene, Oregon, USA) according to the manufacturer's protocol using a 96-well microplate fluorometer FluoroCount $^{\mathrm{TM}}$ (Packard Instruments).

In order to determine the total amount of ovalbumin encapsulated into PLGA-MS, microspheres were incubated 

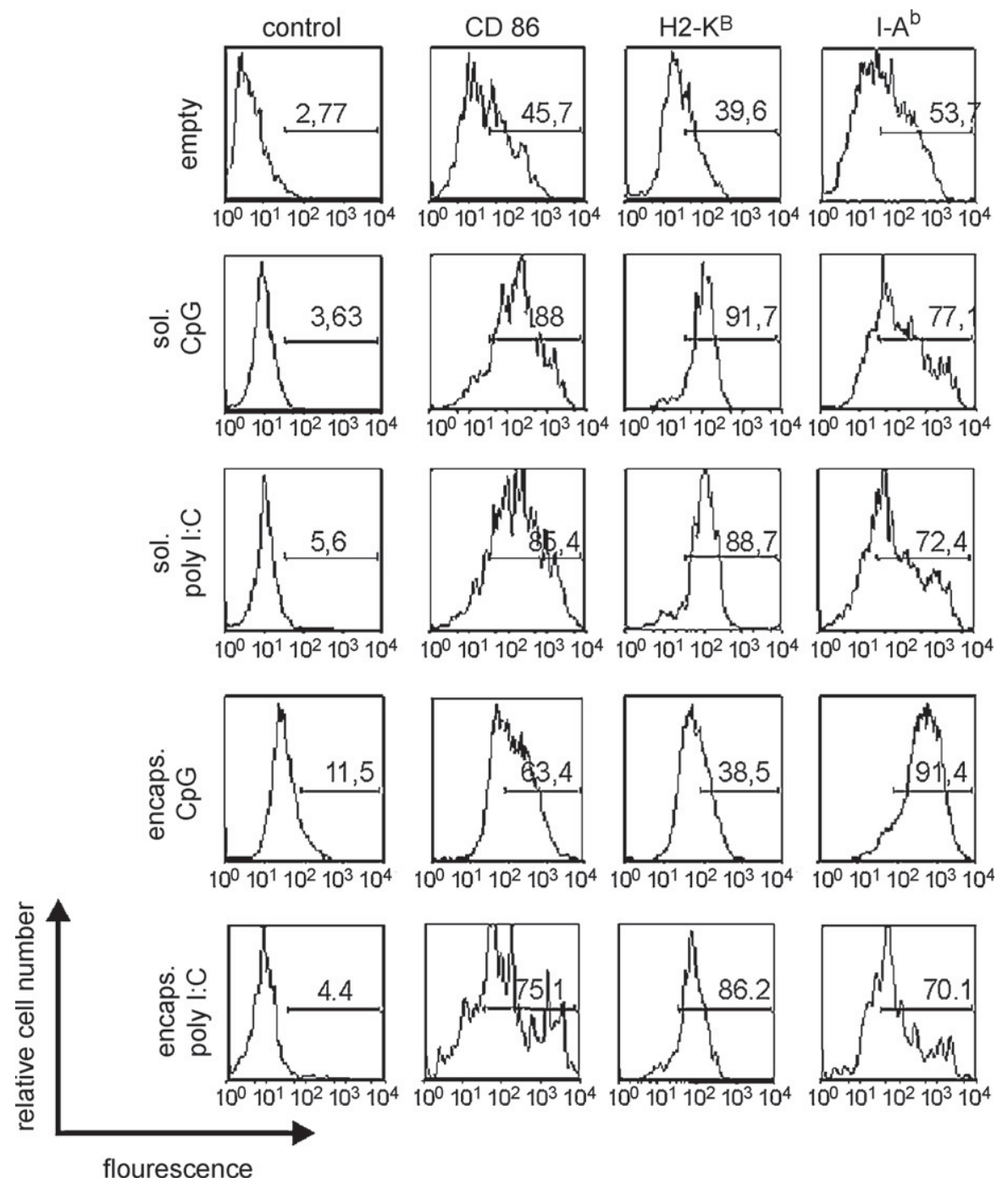

Figure 1 Maturation of BMDCs via encapsulated TLR ligands. Immature BMDCs were coincubated with MSs loaded with CPG oligonucleotide (encaps. CpG) or MS loaded with polyl:C (encaps. polyl:C) or with equivalent amounts of soluble CpG (sol. CpG) or soluble polyl: $\mathrm{C}$ (sol. polyl:C) or with empty microspheres (empty) for $18 \mathrm{~h}$. Subsequently surface expression of $C D 86, \mathrm{H}-2 \mathrm{~K}^{\mathrm{b}}$, and $\mathrm{H}-2 \mathrm{IA} \mathrm{A}^{\mathrm{b}}$ or isotype control (control) was analysed by flow cytometry. A representative experiment out of three experiments with similar outcome is shown.

in $6 \mathrm{~N} \mathrm{HCl}$ for $2 \mathrm{~h}$ at $95^{\circ} \mathrm{C}$ followed by neutralization with $\mathrm{NaOH}$ and Trizma $^{\circledR}$ base (Sigma). As a standard, grade $\mathrm{V}$ ovalbumin (Sigma) was treated similarly in varying concentrations. Protein concentration in the solution was determined using the micro-BCA ${ }^{T M}$ Protein Assay Kit (Pierce, Rockford, IL). Encapsulation efficacy for PLGA-MS containing ovalbumin was $57 \pm 4.5 \%$ and for the batches in which ovalbumin was coencapsulated with CpG oligonucleotides $45 \pm 18.3 \%$.

\section{Generation of BMDCs and maturation mediated by encapsulated adjuvants}

For preparation of murine CD11 $\mathrm{c}^{+} \mathrm{DC}$, femurs of $\mathrm{C} 57 \mathrm{BL} / 6$ mice were taken and their bone marrow isolated by flushing with PBS. Erylysis was performed using $\mathrm{NH}_{4} \mathrm{Cl}$. Afterwards, cells were cultured in 1640 RPMI medium supplemented with $10 \%$ FCS, 2-ME and 10\% supernatant of GM-CSF transfected X63Ag8-653-cells. Cells were harvested after culturing for 5 days in six-well plates. The proportion of CD11 ${ }^{+}$cells was approximately $70 \%$. For maturation, cells were cultured in the presence of LPS $(10 \mu \mathrm{g} / \mathrm{ml})$, polyl:C $(20 \mu \mathrm{g} / \mathrm{ml})$, or CpG $(6 \mu \mathrm{g} / \mathrm{ml})$ for $18 \mathrm{~h}$. To test maturation mediated by TLR ligand loaded MS, cells were incubated with either $4 \mathrm{mg} / \mathrm{ml}$ of MS containing polyl: $C$ or $1 \mathrm{mg} / \mathrm{ml}$ MS containing CpG for $18 \mathrm{~h}$. Afterwards, the cells were sorted for $\mathrm{CD}_{11} \mathrm{c}^{+}$and stained for $\mathrm{H}-2 \mathrm{~K}^{\mathrm{b}}$ (clone AF6-88.5), CD86 (clone GL1), and H-2IA ${ }^{\mathrm{b}}$ (clone AF6-120.1). All antibodies were purchased from BD Pharmingen. FACS analysis was performed with a FACScan ${ }^{T M}$ using CellQuest ${ }^{T M}$ software (BD Biosciences, Heidelberg) and the data was subsequently analysed by Flowjo ${ }^{T M}$ software (Tree Star, Ashland, Oregon). 

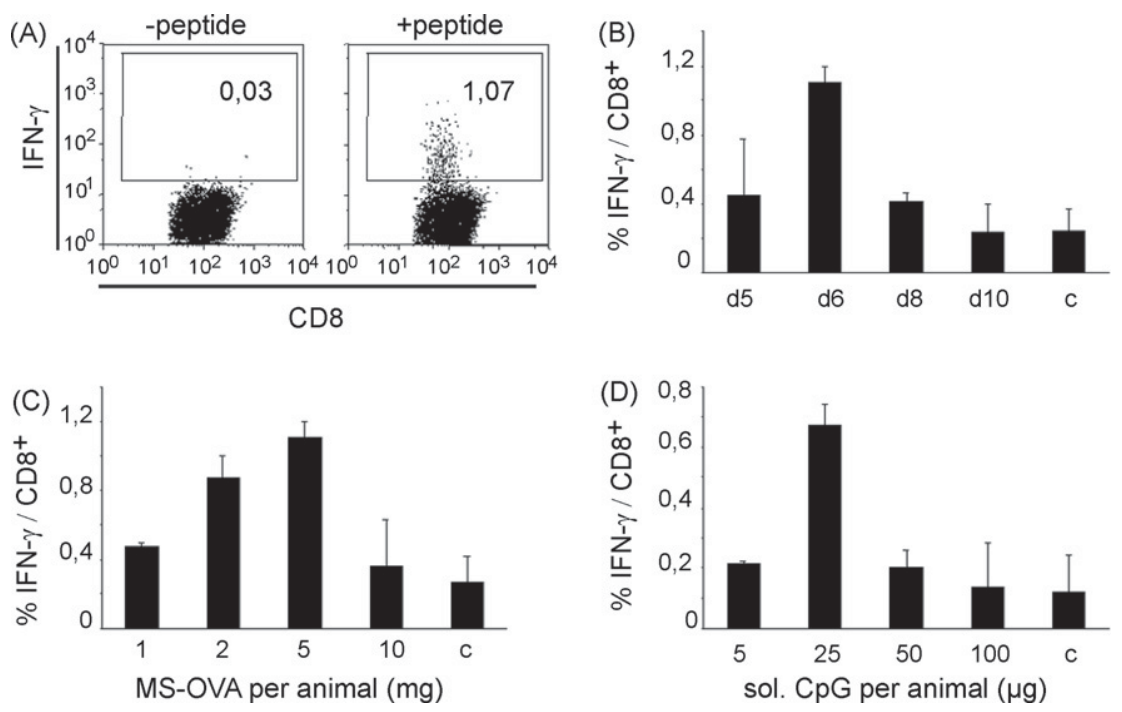

Figure 2 Dose response and kinetics of $\mathrm{CD}^{+}$response after vaccination with microsphere formulations. (A) Flow cytometry dot plot of IFN- $\gamma$ secreting CD8 $8^{+}$cells from one representative animal 6 days after injection of $5 \mathrm{mg}$ MS-OVA (containing $50 \mu \mathrm{g}$ ovalbumin/mg MS) and $25 \mu$ g soluble CpG oligonucleotide 1826. Intracellular IFN- $\gamma$ and CD8 staining of splenocytes was performed after $5 \mathrm{~h}$ of restimulation in the presence (+ peptide) or absence (- peptide) of SIINFEKL peptide. (B) Percentage of IFN- $\gamma$ secreting $\mathrm{CD}^{+}$cells of animals (two mice per group) immunized with a mixture of $5 \mathrm{mg}$ of ovalbumin-loaded MS ( $50 \mu \mathrm{g}$ ovalbumin/mg MS) and $25 \mu \mathrm{g}$ soluble CpG oligonucleotide. At 5, 6, 8, and 10 days (d5-d10) after immunization, splenocytes were isolated, and IFN- $\gamma /$ CD8 staining was performed as outlined above; cells restimulated without peptide served as control (letter C). (C) Percentage of IFN- $\gamma$ secreting $\mathrm{CD} 8^{+}$cells of animals (two mice per group) immunized s.c. with a mixture of $1,2,5$, or $10 \mathrm{mg}$ of albumin-loaded $\mathrm{MS}$ (50 $\mu \mathrm{g}$ ovalbumin/mg MS) and $25 \mu \mathrm{g}$ soluble CpG oligonucleotide. Intracellular IFN- $\gamma / \mathrm{CD}^{+}$staining was performed as outlined above at day 6 after immunization; cells restimulated without peptide served as control (letter C). (D) Percentage of IFN- $\gamma$ secreting CD8 ${ }^{+}$ cells of animals (two mice per group) immunized s.c. with a mixture of $5 \mathrm{mg}$ of ovalbumin-loaded MS ( $50 \mu \mathrm{g}$ ovalbumin/mg MS) and $5,25,50$, or $100 \mu$ g soluble CpG oligonucleotide. After 6 days, intracellular IFN- $\gamma /$ CD8 staining of splenocytes was performed as described above; cells restimulated without peptide served as control (letter $\mathrm{c}$ ).

\section{Intracellular cytokine staining}

C57BL/6 mice were immunized by s.c. injection of MS dispersed in $400 \mu \mathrm{l}$ PBS in the base of the tail (three mice per group). Six days later, splenocytes were isolated and incubated with $10 \mu \mathrm{M}$ SIINFEKL peptide (Eurogentec, Cologne, Germany) in the presence of brefeldin A $(10 \mu \mathrm{g} / \mathrm{ml}$, Sigma-Aldrich) for $5 \mathrm{~h}$. The cells were then washed and stained with PE-Cy5-conjugated rat $\operatorname{lgG} \alpha$ CD8 $\alpha$ antibody (BD Biosciences Pharmingen, Clone 53-6.7) for $20 \mathrm{~min}$ at $4{ }^{\circ} \mathrm{C}$. The cells were washed before they were fixed with $1 \%$ paraformaldehyde in PBS for $25 \mathrm{~min}$ at room temperature. After washing, the cells were labeled intracellularly with FITC-conjugated rat $\alpha$-IFN- $\gamma$ antibody (clone XGM1.2, diluted in PBS/0.1\% Saponin) at $4{ }^{\circ} \mathrm{C}$ overnight. After a final washing step, cells were resuspended in $200 \mu \mathrm{l}$ PBS and analysed by flow cytometry.

\section{MHC tetramer analysis}

The $\mathrm{H}-2 \mathrm{~K}^{\mathrm{b}}$ /SIINFEKL tetramers used in this study were generated as described before [17]. For MHC tetramer staining, splenocytes were stained with PE-labeled SIINFEKL/H- $2 \mathrm{~K}^{\mathrm{b}}$ tetramer for $25 \mathrm{~min}$ at $4{ }^{\circ} \mathrm{C}$ and subsequently with PE-Cy5conjugated rat $\alpha-\operatorname{CD} 8 \alpha-\lg G$ for $20 \mathrm{~min}$ at $4{ }^{\circ} \mathrm{C}$. Cells were washed twice and measured by flow cytometry.

\section{In vivo cytotoxicity assay}

Cytotoxic activity of $\mathrm{CD}^{+}$cells in vivo was assessed as described elsewhere [18]. Briefly, splenocytes from naive mice were pulsed with $10 \mu \mathrm{M}$ SIINFEKL peptide. The pulsed cells were stained with $10 \mu \mathrm{M}$ carboxyfluorescein succinimidyl ester (CFSE), while unpulsed cells were stained with $0.3 \mu \mathrm{M}$ CFSE. Immediately before injection, both cell populations were mixed, and a total number of $1 \times 10^{7}$ cells were injected i.v. into mice. After $18 \mathrm{~h}$, splenocytes were prepared and analysed by flow cytometry. The percentage of cytolysis was calculated as follows: $100-[(\%$ peptide pulsed cells in vaccinated mice/\% unpulsed cells in vaccinated mice)/(\% peptide pulsed cells in control mice/\% unpulsed cells in control mice) $] \times 100$.

\section{Cytolytic assays}

C57BL/ 6 mice were immunized by s.c. injection of MS dispersed in $400 \mu \mathrm{l}$ PBS in the base of the tail (three mice per group). Six days later, splenocytes were isolated and used as effectors in a primary chromium release assay as previously described [19]. Target cells were EL4 T cells $\left(\mathrm{H}-2^{\mathrm{b}}\right)$ either left unpulsed as negative control (data not shown) or externally loaded with the SIINFEKL peptide. 

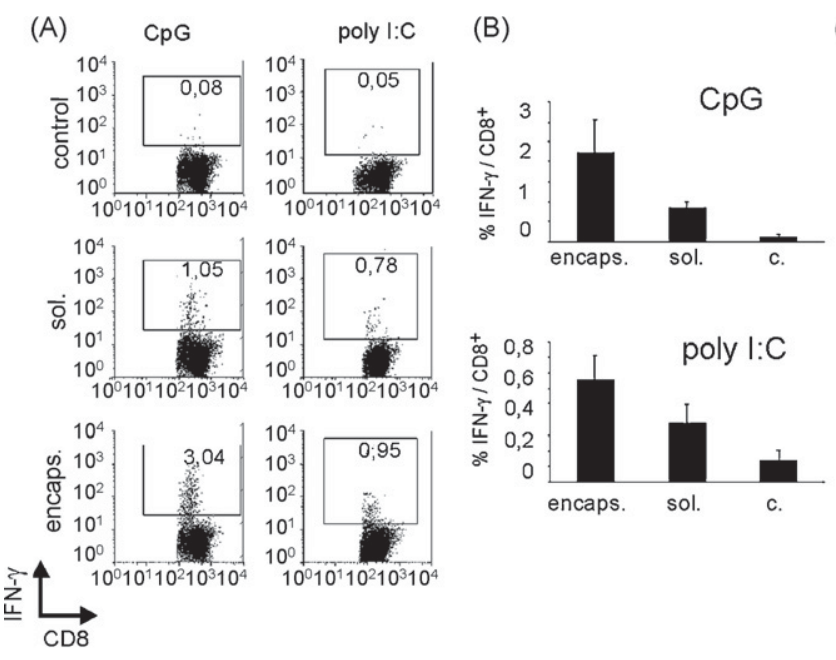

(C)
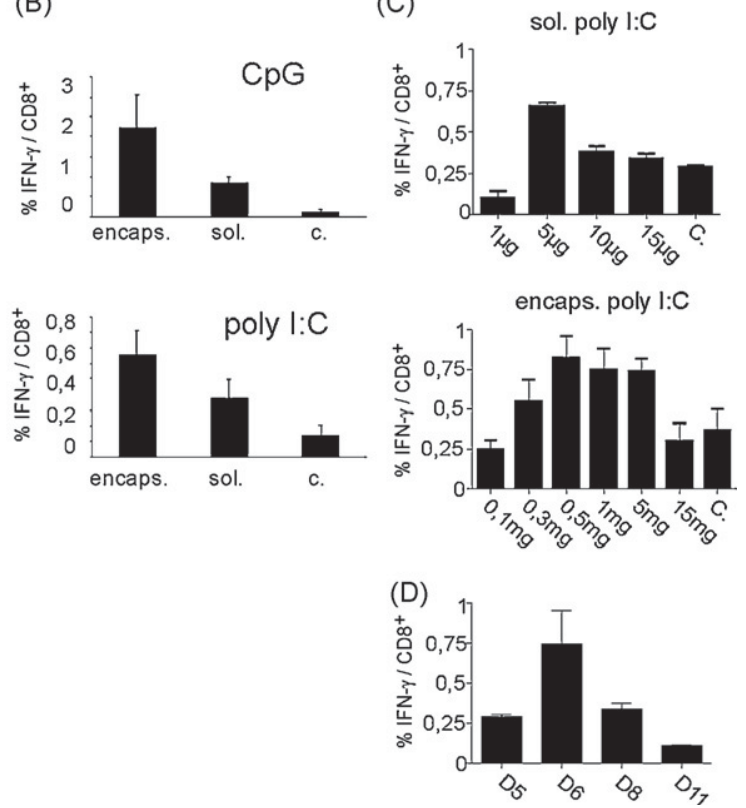

Figure 3 Encapsulated TLR ligands lead to increased cross-priming. (A) Flow cytometry dot plot of IFN- $\gamma$ secreting CD8 ${ }^{+}$cells from one representative animal at 6 days after s.c. injection of physical mixtures of $5 \mathrm{mg}$ MS-OVA (corresponding to $250 \mu \mathrm{g}$ ovalbumin) with either $25 \mu \mathrm{g}$ CpG oligonucleotide or polyl:C in soluble (sol.) or miroencapsulated (encaps.) form. After 6 days, splenocytes were stained after restimulation with SIINFEKL peptide for intracellular IFN- $\gamma$ and CD8, as in Fig. 2. Cells restimulated without peptide served as controls. (B) Quantitative representation of all flow cytometry data, exemplified for one animal in (A), for coinjected CpG oligonucleotide (upper panel) or polyl:C (lower panel); cells restimulated without peptide served as control (C). Values are the means of three mice \pm S.D. Values of $p$ were determined by unpaired Student's $t$-test and were considered to be statistically significant with a $p$ value for the sol. and encaps. data of 0.0158 (for CpG) and 0.0022 (for polyl:C). (C) Titration of soluble and encapsulated polyl:C. Mice were immunized with $5 \mathrm{mg}$ MS-OVA together with indicated amounts of either soluble polyl:C (upper panel) or microencapsulated polyl:C (lower panel). After 6 days, the CTL response was determined as in A. (D) Kinetics of CTL induction after immunization with $5 \mathrm{mg}$ MS-OVA and $0.5 \mathrm{mg}$ MS-polyl:C. At the indicated days after inoculation, the SIINFEKL-specific CTL response was determined with intracellular IFN- $\gamma$ staining. The experiments have been repeated twice, yielding similar results.

\section{Virus protection assay}

To assay viral protection, animals were challenged on day 6 after vaccination with $\mathrm{MS}$ with $2 \times 10^{6}$ pfu recombinant vaccinia virus coding for ovalbumin (rVV-OVA) by intraperitoneal injection (kindly contributed by Dr. Jonathan Yewdell, NIH, Bethesda, MD). Four days later, ovaries were taken, and a virus plaque assay was performed on BSC-40 cells.

\section{Statistical analysis}

To statistically assess differences between groups, Student's unpaired $t$-test was performed using the GraphPad software. A $p$-value $<0.05$ was considered statistically significant for all analyses.

\section{Results}

\section{Maturation of BMDCs by microencapsulated TLR ligands}

The hydrolysis of PLGA-MS leads to the production of glycolic and lactic acid and concomitant acidification of PLGA-MS, which may harm microencapsulated proteins or nucleic acids [20]. Hence, we tested whether PLGA-MS con- taining the TLR9 ligand CpG oligonucleotide 1826 [21] or the TLR3 ligand polyl:C were capable to phenotypically mature mouse bone marrow-derived dendritic cells (BMDCs). After 5-6 days of culture in GM-CSF, BMDCs were incubated for $18 \mathrm{~h}$ either with MS containing either microencapsulated CpG oligonucleotide 1826 or microencapsulated polyl:C. BMDCs cocultured with empty MS and cells treated with corresponding amounts of soluble polyl: $\mathrm{C}$ or soluble $\mathrm{CpG}$ oligonucleotide served as negative and positive controls, respectively. Maturation analysis was performed by staining for CD86, MHC-I, and MHC-II. As shown in Fig. 1, both microencapsulated and soluble adjuvants, but not empty MS, led to upregulation of CD86, MHC-I, and MHC-II. Although the upregulation of maturation markers was slightly less pronounced when microencapsulated adjuvants were used, it appeared that microencapsulation largely preserved the adjuvant properties of polyl:C or CpG oligonucleotide.

\section{Optimizing the parameters for cross-priming with microencapsulated antigen}

To investigate how cross-priming is influenced by particulation of antigen in vivo we used ovalbumin as a model antigen for microencapsulation into biodegradable PLGA-MS. Ovalbumin-loaded MS (MS-OVA) were injected 
subcutaneously either alone or in a mixture with soluble CpG oligonucleotide into the base of the tail of C57BL/6 mice. On different days after injection, splenocytes were recovered, and after $5 \mathrm{~h}$ of restimulation with the $\mathrm{H}-2 \mathrm{~K}^{\mathrm{b}}$ restricted SIINFEKL epitope of ovalbumin in vitro, spleen cells were stained for $\mathrm{CD}^{+}$and intracellular IFN- $\gamma$. As shown in Fig. $2 \mathrm{~A}$ and $B$, SIINFEKL-specific responses could be detected on day 6 after vaccination, but neither 1 day earlier nor on days 8 or 10 after vaccination. To further characterise our system, different amounts of MS-OVA were injected s.c. and the OVAspecific CTL response was assessed on day 6 by intracellular IFN- $\gamma$ staining. The strongest responses were detected when $5 \mathrm{mg}$ of MS-OVA, containing a targeted amount of $250 \mu \mathrm{g}$ (i.e. $5 \%, w / w)$ ovalbumin, were used per animal (C). Surprisingly, IFN- $\gamma$ production significantly diminished, when higher amounts were injected. This overdose effect was also obtained when half of the amount of PLGA loaded with the double amount of ovalbumin was injected (data not shown). Whether this decline occurred because of functional exhaustion of $\mathrm{CD}^{+}$cells by overloading the system with antigen remains to be investigated. In addition to the antigen dose finding, we also titrated the amount of soluble CpG oligonucleotide coinjected with MS-OVA. The response was optimal when $25 \mu \mathrm{g}$ of soluble CpG oligonucleotide was coinjected per animal, but it also decreased at higher doses of CpG oligonucleotide (D).

\section{Microencapsulation of TLR ligands into PLGA-MS enhances the CTL response}

Next, we examined whether microencapsulation of TLR ligands leads to a further enhancement of $C D 8^{+}$-lymphocyte activation. For this purpose PLGA-MS loaded with either CpG oligonucleotide 1826 (MS-CpG) or polyl:C (MS-polyl:C) were prepared. Animals received either a mixture of MS-OVA and MS-CpG or a mixture of MS-OVA and MS-polyl:C and the effect was compared to the coapplication of MS-OVA with equivalent amounts of the soluble adjuvants. On day 6 after injection, activation of SIINFEKL-specific splenocytes was assessed by intracellular IFN- $\gamma$ staining. Remarkably, both microencapsulated TLR ligands led to a twofold increase in the generation of OVA-specific CTLs as compared to the coinjection of soluble TLR ligands (Fig. $3 \mathrm{~A}$ and $\mathrm{B}$ ). Although this effect could be observed for both TLR ligands to the same extent, the overall response obtained after coinjection of $\mathrm{CpG}$ oligonucleotide was consistently stronger than the CTL yield obtained when using polyl: $C$ as an adjuvant. To exclude that polyl: $C$ was used in a suboptimal concentration, we coinjected mice with $5 \mathrm{mg}$ MS-OVA together with titrated amounts of either soluble polyl:C or microencapsulated polyl:C. Optimal CTL responses were obtained with $5 \mu \mathrm{g}$ soluble polyl: $\mathrm{C}$ and $0.5 \mathrm{mg}$ MS-polyl:C (containing $2.5 \mu \mathrm{g}$ or $0.5 \%, \mathrm{w} / \mathrm{w}$ of polyl:C) which confirmed that higher $\mathrm{CTL}$ responses can be achieved with less adjuvant when it is applied in microencapsulated form. We then determined the kinetics of CTL responses after vaccination with $5 \mathrm{mg}$ MS-OVA and $0.5 \mathrm{mg} M S$-polyl: $C$ and found that - similar to vaccination with CPG oligonucleotides (Fig. 2B) - a maximal CTL response occurred on day 6 after immunization (Fig. 3D).
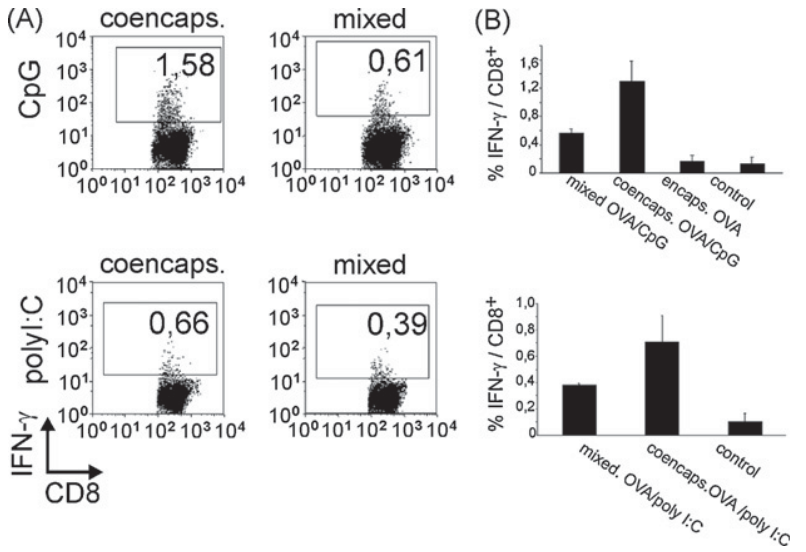

Figure 4 Coencapsulated TLR ligand and antigen enhance IFN- $\gamma$ production in $\mathrm{CD}^{+}$-lymphocytes. (A) Flow cytometry dot plot of IFN- $\gamma$ production in splenocytes restimulated with SIINFEKL peptide on day 6 after s.c. vaccination of mice with physical mixtures of $5 \mathrm{mg}$ MS-OVA with either $5 \mathrm{mg} \mathrm{MS-CpG}$ or $5 \mathrm{mg}$ MS-polyl:C (mixed), or with $5 \mathrm{mg}$ of single MS formulations containing either coencapsulated OVA and CpG or coencapsulated OVA and polyl:C (coencaps.). The MS contained $5 \mu \mathrm{g} / \mathrm{mg}$ adjuvants and $50 \mu \mathrm{g} / \mathrm{mg}$ ovalbumin. (B) Quantitative representation of all flow cytometry data, exemplified for one animal in (A), for CpG oligonucleotide (upper panel) and polyl:C (lower panel). Values obtained after vaccination with MS-OVA alone are also shown; cells restimulated without peptide served as control. Values are the means of three mice \pm S.D. Values of $p$ were determined by unpaired $t$-test for the coencaps. vs. the mixed settings and were considered to be statistically significant with a $p$ value of 0.0120 (upper panel) and 0.0503 (lower panel). The experiments have been repeated three times, yielding similar results.

\section{Coencapsulated antigen and TLR ligand in PLGA-MS achieve efficient cross-priming and the most potent CTL responses in vivo}

Blander and Medzhitov have shown in their recent publication [8] that the efficiency of antigen presentation on MHC-II in vitro is dependent on the presence of TLR ligand and antigen within the same particle. In order to investigate whether in vivo cross-priming is also influenced by close proximity of antigen and TLR ligand we coencapsulated ovalbumin and TLR ligands within one and the same microsphere preparation. The efficiency of crosspriming was again assessed after injection as described above. In fact, Fig. 4A reveals that coencapsulated ovalbumin and $\mathrm{CpG}$ oligonucleotide achieved a SIINFEKL-specific IFN- $\gamma$ response of $\mathrm{CD}^{+}$-lymphocytes that was twice as high as that observed after vaccination with a mixture of two MS formulations each containing separately equivalent amounts of adjuvant and antigen. The same effect was observed when using polyl: $C$ as an adjuvant but the obtained CTL responses were again significantly weaker than the ones obtained with CpG oligonucleotide (B). Vaccination with MS-OVA alone yielded virtually no CTL response above background, which is consistent with the inability of PLGA-MS to induce DC maturation in the absence of adjuvants. To ascertain that the observed enhancement of 

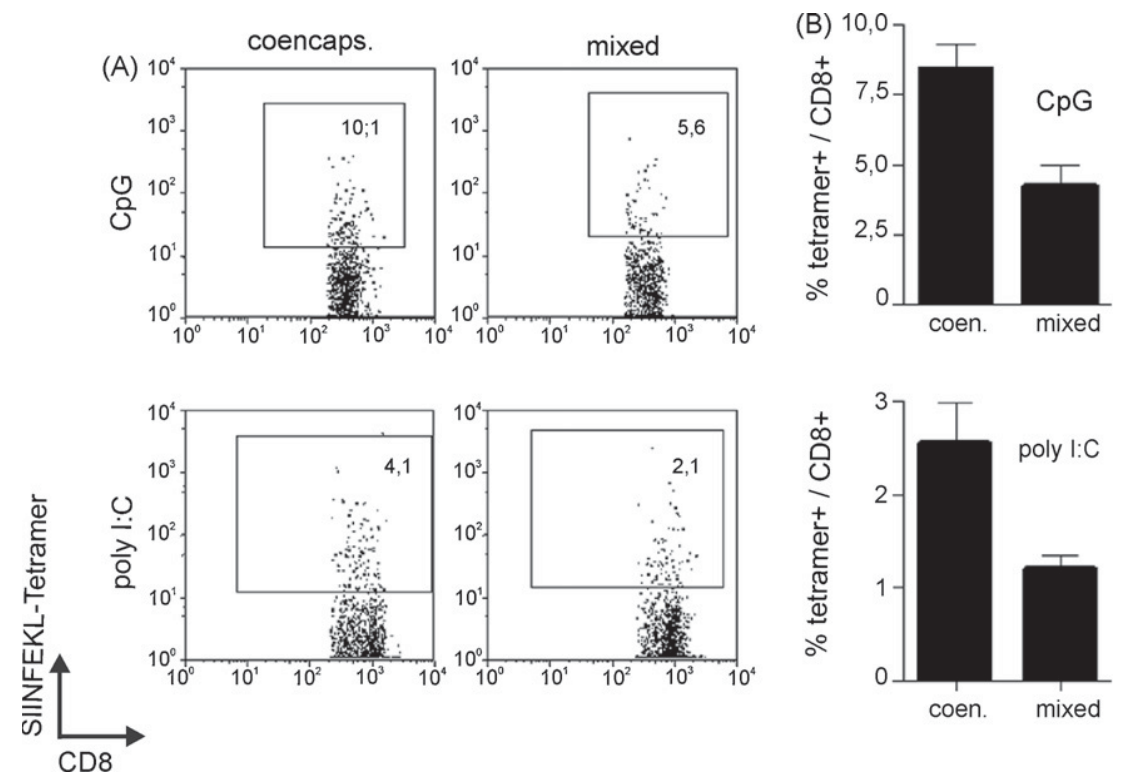

Figure 5 Coencapsulated TLR ligands and ovalbumin lead to high numbers of SIINFEKL/H-2K tetramer-specific CD8 ${ }^{+} \mathrm{T}$ cells. (A) Representative flow cytometry dot plots of splenocytes from mice 6 days after s.c. vaccination with physical mixtures of $5 \mathrm{mg}$ MS-OVA with either $5 \mathrm{mg}$ MS-CpG or MS-polyl:C (mixed) or with $5 \mathrm{mg}$ of single MS formulations containing either coencapsulated OVA and $\mathrm{CPG}$ oligonucleotide or coencapsulated OVA and polyl:C (coencaps.). Plotted are the stainings for $\mathrm{H}-2 \mathrm{~K}^{\mathrm{b}} / \mathrm{SIINFEKL}$ tetramers vs. CD8. Untreated C57BL/ 6 mice served as negative controls and yielded tetramer stainings below $0.5 \%$ each time (data not shown). (B) Quantitative representation of all flow cytometry data, exemplified for one animal in (A), for CpG oligonucleotide (upper panel) and polyl:C (lower panel). Values are the means of three mice \pm S.D. Values of $p$ were determined by unpaired $t$-test and were considered to be statistically significant with a $p$ value of 0.0007 (upper panel) and 0.0472 (lower panel). The experiments have been repeated twice, yielding similar results.

CTL response was not due to a different amount of OVA released when both the adjuvant and antigen were coencapsulated, we tested the in vitro release with different MS formulations. All MS formulations containing ovalbumin with or without adjuvant were incubated for 3 days in PBS, and the supernatant was assayed fluorimetrically. Within 3 days, MS-OVA released $66.7 \pm 4.8 \mu \mathrm{g} / \mathrm{ml}$ ovalbu$\min$ (i.e. $15.3 \pm 1 \%$ of the theoretically loaded amount) whereas the MS with the coencapsulated OVA/CpG released $49.4 \pm 17.6 \mu \mathrm{g} / \mathrm{ml}$ (i.e. $9.9 \pm 3.5 \%$ ), showing that according to Student's $t$-test there existed no significant difference in the early OVA release between these two preparations. The same was observed when CpG release was analysed in the supernatant by staining with Oligreen, a specific fluorescent dye for single-stranded DNA. Within the 3 days of testing, the MS-CpG released $14.4 \pm 4.3 \mu \mathrm{g} / \mathrm{ml}$ of $\mathrm{CpG}$ (i.e. $28.8 \pm 8.6 \%$ ), whereas the MS with the coencapsulated OVA/CpG released $10.5 \pm 0.6 \mu \mathrm{g} / \mathrm{ml}$ (i.e. $21 \pm 1.2 \%$ ) of the adjuvant also showing no significant difference between the two preparations. To determine the total content of OVA in MS-OVA and MS-OVA/CpG, we hydrolyzed the MS completely in $\mathrm{HCl}$ and determined the protein content after neutralization (see materials and methods). This analysis, which provides a measure of the effective encapsulation in relation to the theoretically targeted encapsulation, revealed that the efficiency for MS-OVA was $57 \pm 4.5 \%$ and for MS-OVA/CpG $45 \pm 18.3 \%$. We hence conclude that the increased $\mathrm{CD}^{+}$responses were not due to differences in the effective content of OVA or the amount of antigen or CpG oligonucleotide released from the MS containing coencapsulated as compared to singly encapsulated components.

So far we had only used intracellular IFN- $\gamma$ production as a read out for CTL activation. Since it is known that not all antigen-specific CTL can be induced to produce IFN- $\gamma$ during a 5 -h in vitro stimulation with peptide, we used SIINFEKL/H-2K ${ }^{\mathrm{b}}$ tetramer stainings to assess the overall generation of SIINFEKL-specific CTL. As indicated in Fig. 5, we achieved an average of approximately 9\% of SIINFEKL-specific $\mathrm{CD}^{+}$-lymphocytes when a single PLGA-MS preparation was administered that contained both the ovalbumin and $\mathrm{CpG}$ oligonucleotide. Approximately half of the response was detected when a mixture of the two MS preparations containing the same amounts of separately microencapsulated antigen and adjuvant was administered. In agreement with the IFN- $\gamma$ assay (Fig. 4), the responses to polyl:C were generally lower, but also showed a twofold enhancement of the CTL responses when adjuvant and antigen were coencapsulated (Fig. 5).

In order to assess the cytolytic capacity of MS containing ovalbumin and CpG oligonucleotide, we performed an in vivo cytotoxicity assay with animals, which were previously vaccinated with coencapsulated or individually microencapsulated OVA and CPG. In this experiment, vaccinated or untreated control mice were injected on day 6 with unpulsed target cells stained with a low concentration of the fluorescent dye CFSE, and SIINFEKL-pulsed target cells stained with a high concentration of CFSE. In animals that had received MS with coencapsulated OVA/CPG 
nearly all peptide-pulsed target cells were killed after $18 \mathrm{~h}$, while unpulsed target cells were not diminished (Fig. 6A and $B$ ). By contrast, animals that had received the MS with individually microencapsulated OVA and CpG lysed only incompletely the peptide-pulsed target cells; this indicates that the cytolytic response was weaker when antigen and adjuvant were administered in separate particles. The latter insight was also confirmed in primary cytolytic chromium release assays in vitro. Splenocytes from mice vaccinated with MS with coencapsulated OVA/CpG lysed SIINFEKL-pulsed EL4 target cells significantly better than splenocytes from mice vaccinated with MS with individually microencapsulated OVA and $\mathrm{CpG}$ whereas vaccination with empty MS yielded no SIINFEKL-specific responses (C).

\section{Vaccination with PLGA-MS protects from infection with vaccinia virus}

Protection from vaccinia virus depends upon the activity of $\mathrm{CDB}^{+} \mathrm{T}$ cells in C57BL/6 mice [22]. To compare the antiviral capacity of $\mathrm{CD}^{+}$-lymphocytes induced by coencapsulated and separately microencapsulated ovalbumin and CpG oligonucleotide, mice vaccinated as described above were challenged with a high dose of recombinant vaccinia virus encoding ovalbumin (rVV-OVA). Viral titers were determined 4 days later in the ovaries (Fig. 7). We found that coencapsulated OVA/CpG provided partial protection against vaccinia virus already at a dose of $2.5 \mathrm{mg}$ whereas $5 \mathrm{mg}$ of the MS mixture had to be applied to achieve an effect. Untreated animals or animals immunized with lower amounts of MS contained high titers of rVV-OVA in the ovaries. It has been shown, that CpG oligonucleotide injection alone can be sufficient to protect animals against viral infections [23]. Consequently, we investigated whether protection was antigen-specific or simply based on unspecific activation of the innate immune system via CPG oligonucleotide. Although the virus titer was significantly decreased when MS-CpG was administered without antigen, full protection was only achieved when antigen was present. Taken together, we conclude that also for protection against rVVOVA challenge, the coencapsulation of antigen and adjuvant in the same MS was more potent than the application of mixed MS separately charged with antigen and adjuvant.

\section{Discussion}

Dendritic cells continuously sample their environment and thereby simultaneously capture microbial antigens, selftissue and harmless environmental proteins. This situation poses the question how DCs manage to restrict their stimulation to the microbe and avoid the danger of initiating autoimmune responses. For MHC class II presentation it has recently been shown by Blander and Medzhitov, that DCs distinguish between self- and nonself-antigens in phagosomes by selectively maturing endosomes that contain the TLR4 ligand LPS, which is accompanied by sequential fusions with lysosomes and ultimately results in enhanced presentation of epitopes on MHC class II molecules [8]. Because the capacity to cross-present exogenous antigens on MHC class I molecules is one of the most striking specialisa-
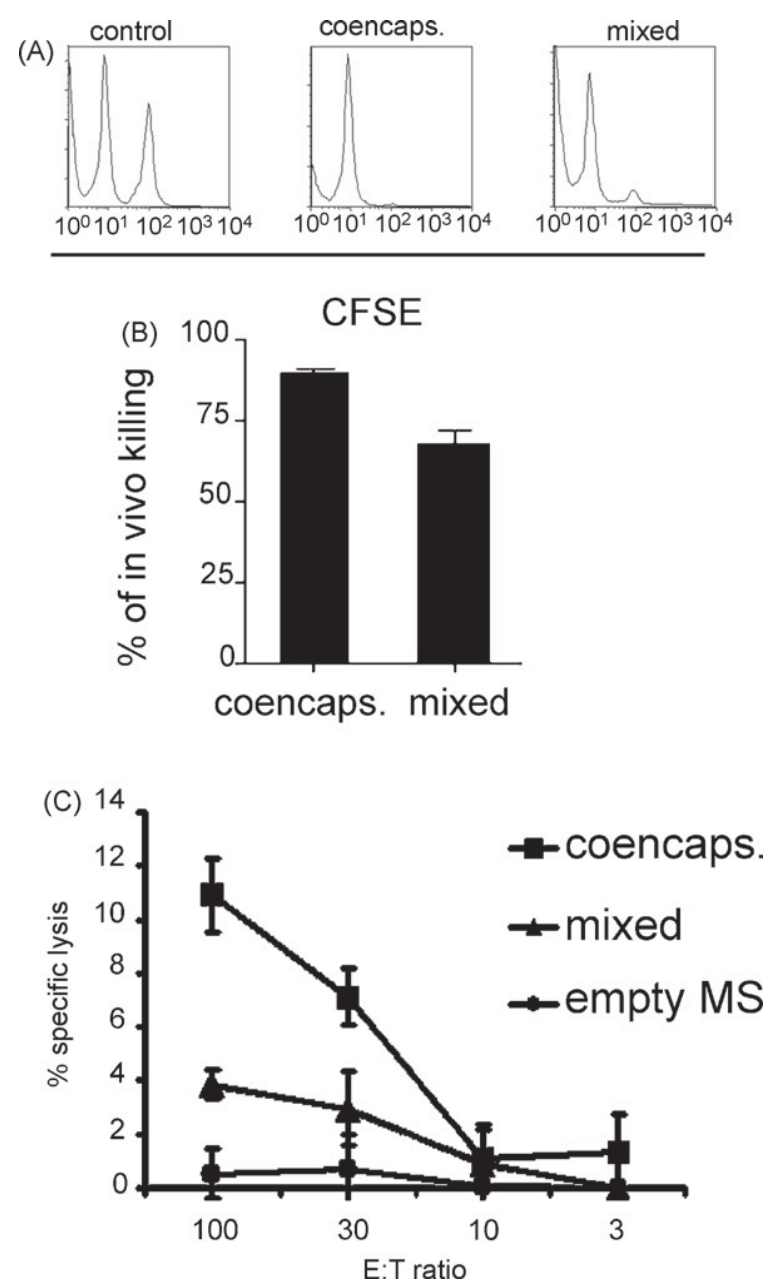

Figure 6 Coencapsulated TLR ligand and antigen induce cytotoxicity in vivo and in vitro. (A and $\mathrm{B}$ ) Target cells of in vivo cytotoxicity assays were prepared from syngeneic splenocytes that were either externally loaded with SIINFEKL peptide and strongly labeled with CFSE or were not loaded with peptide and weakly labeled with CFSE. The target cells were adoptively transferred into C57BL/ 6 mice 6 days after s.c. vaccination with a physical mixture of $5 \mathrm{mg} M \mathrm{MS}-\mathrm{OVA}$ and $5 \mathrm{mg} \mathrm{MS}-\mathrm{CpG}$ (mixed) or with $5 \mathrm{mg}$ of a single MS formulation containing coencapsulated OVA and CPG (coencaps.). Untreated animals served as controls. Spleens were harvested $18 \mathrm{~h}$ later and analysed for CFSE fluorescence by flow cytometry. (A) One representative animal per group is shown in the upper histogram. (B) Quantitative representation of all flow cytometry data, exemplified for one animal in (A). Values represent percent in vivo cytolysis calculated as detailed in the materials and methods section. The values are the means of three mice \pm S.D. Values of $p$ were determined by unpaired $t$-test and are considered to be statistically significant with a $p$ value of 0.00354 . The experiment was repeated twice with a similar outcome. (C) Chromium release assay using splenocytes from mice 6 days after vaccination with mixed or coencapsulated MS as outlined above. MS devoid of OVA and adjuvant served as negative control (empty). EL4 cells loaded externally with SIINFEKL peptide served as target cells. A representative experiment out of four experiments with similar outcome is shown. 


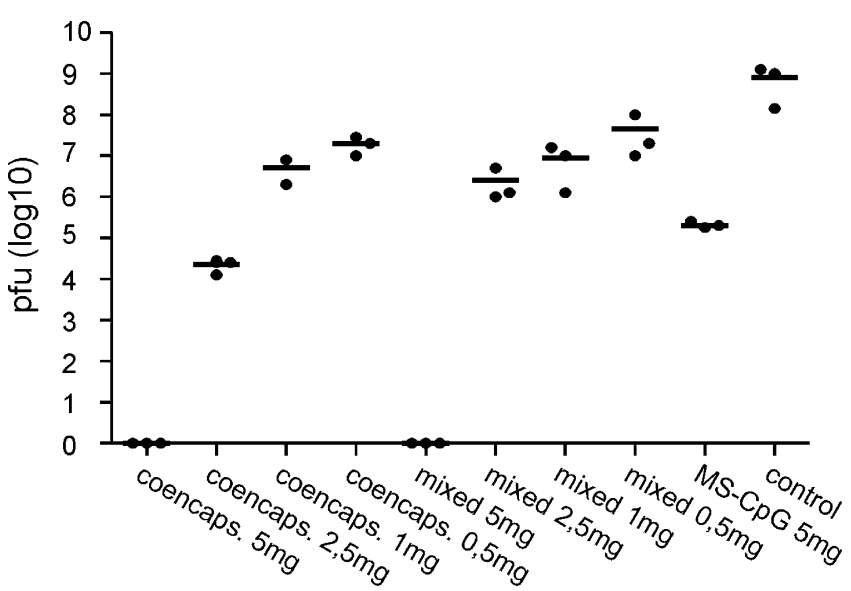

Figure 7 Induction of protective immunity by PLGA-MSbased vaccination. Groups of three female C57BL/ 6 mice were immunized s.c. either with a physical mixture of the indicated amounts of MS-OVA and MS-CPG (mixed) or with the indicated amounts of a single MS formulation containing coencapsulated OVA and CpG (coencaps.), or else with $5 \mathrm{mg}$ MS-CpG alone (MS$\mathrm{CpG}$ ) or empty MS (control). Six days after vaccination, mice were challenged i.p. with $2 \times 10^{6}$ pfu rVV-OVA, and 4 days later, ovaries were recovered for determination of the viral titer. Individual mice and the median values per group are shown. One out of three experiments with similar outcome is shown.

tions of dendritic cells we focused on the question whether for cross-presentation of particulate antigens there is a similar requirement to coencapsulate TLR ligand and antigen.

Initially, we had some doubt whether coencapsulation of adjuvant and antigen matters, because we had shown that the uptake of PLGA-MS loaded with influenza virus matrix protein by immature human DC in vitro followed by their maturation with soluble TLR ligands or proinflammatory cytokines led to full phenotypic as well as functional maturation [15]. Maturation was evidenced by an increase in allostimulation of naïve $\mathrm{CD}^{+}$or $\mathrm{CD}^{+} \mathrm{T}$ cells, enhanced cytokine secretion, reduced phagocytosis, and the onset of CCR7-directed migration. These mature DC were readily capable to stimulate CTL specific for influenza virus matrix protein and $T$ helper cells specific for tetanus toxoid. From these experiments it did not seem to be pivotal that the maturation stimulus is provided in physical association with the antigen within a particle, but this issue has not been addressed in a quantitative and comparative manner. For soluble protein antigens it has previously been shown that cross-priming in mice and even in primates is more efficient if an adjuvant like $\mathrm{CpG}$ oligonucleotide or other immunostimulatory DNA sequences were chemically linked to an antigen [24-27]. Soluble proteins, however, are notoriously poor substrates for cross-presentation and their uptake and trafficking differs from that of particulate material [28]. For virus-like particles it has been shown that more potent CTL responses were obtained when nonmethylated CpG motifs were packaged into the particles rather than merely coinjected [29]. It was argued at that time that the CpG oligonucleotides were protected from DNAses and that this effect probably accounted for the improved immunogenicity. A further hint was provided by Reis e Sousa and colleagues who showed that cross-priming of cell-associated antigens is more potent, when the cells were either virus infected or loaded with polyl:C. It was deduced that TLR3 triggering is important for cross-priming by $\mathrm{DC}$ which by itself is not unexpected as DC maturation is believed to be a prerequisite for T cell activation [30]. For PLGA-MS it has been shown that surface coating or micro-coencapsulation of an adjuvant and an antigen yields better antibody titers in vaccinated animals [31-33] or better $T$ helper cell proliferation and cytokine secretion in vitro [34], but the generation of CTLs has not been investigated. All these studies did not directly address the question whether an adjuvant and antigen must be colocalized within one and the same particle in order to optimally elicit cross-priming.

Stimulated by the seminal discovery of Blander and Medzhitov [8], we decided to use PLGA-MS to address this issue for cross-priming. PLGA-MS are ideally suited for this purpose, because they can accommodate nucleic acids and proteins, they release their content in an aqueous environment, as for instance in the endosome, and they can be tailored to a size that favors the phagocytic uptake of one rather than two or several MS into a single endosome. Electron microscopic images of human DC that had phagocytosed PLGA-MS suggested indeed that every MS was individually surrounded by a double membrane and that approximately three to eight MSs were taken up per cell [30]. Therefore, we can test in this system whether efficient CTL stimulation can be achieved if adjuvant-loaded MS and antigen-loaded MS are included into separate endosomes by an individual cell. Moreover, by quantitatively comparing the CTL responses obtained when mice were immunized either with mixtures of MS-OVA with either MS-CpG or MS-polyl:C, or with coencapsulated TLR ligand and antigen (MS-CpG /OVA or MS-polyl:C/OVA), we were able to discriminate effects like the protection of an adjuvant within MS from the effect of linking antigen and adjuvant. Using four different read-out systems that reflect (i) the specificity of CTL for the SIINFEKL peptide presented on $\mathrm{H}-2 \mathrm{~K}^{\mathrm{b}}$ (MHC tetramer stain, Fig. 5), (ii) the ability to stimulate CTL to produce IFN- $\gamma$ (intracellular cytokine staining, Fig. 4), (iii) the lysis of SIINFEKL-charged target cells (cytolysis assays, Fig. 6), and (iv) the protection from vaccinia virus infection (Fig. 7), we found that coencapsulated TLR ligand and antigen consistently yielded stronger CTL responses than obtained by administration of a mixture of two MS formulations loaded separately with antigen or adjuvant. This effect was observed for both adjuvants examined, the CPG oligonucleotide and polyl:C, but the adjuvant effect of the TLR9 ligand CpG oligonucleotide was consistently stronger than that of the TLR3 ligand polyl:C; nonetheless, the phenotypic maturation of $B M D C$ in vitro was achieved with both adjuvants (Fig. 1). Since the amounts of separately microencapsulated and coencapsulated antigen and adjuvant were the same and also their release upon hydrolysis of the respective PLGA-MS was equivalent, the mice received the same quantities of adjuvant and antigen with both formulation types. Therefore, the increase in CTL response must have been due to the higher efficiency in antigen presentation achieved by using the single MS formulation with coencapsulated material. Nevertheless, it should be pointed out that the protection of the unstable adjuvants $\mathrm{CpG}$ and polyl: $C$ within MS probably also contributed to the high CTL responses obtained, 
because we found that the encapsulation of the adjuvants yielded approximately twofold higher CTL responses than the corresponding amounts of soluble adjuvant (Fig. 3).

The subcellular mechanism of improved crosspresentation with coencapsulated antigen and adjuvant remains to be clarified. Since the presentation of protein antigens from PLGA-MS is dependent on proteasome and TAP activity and sensitive to brefeldin A [35,36] two out of the three pathways currently discussed for crosspresentation [37], namely the 'ER-phagosome fusion' pathway [38-40] and the 'endosomal class I loading pathway' [41] are unlikely to be involved in cross-presentation from PLGA-MS. More likely, the 'cytosolic escape' pathway $[42,43]$ could apply to antigen delivery via PLGA-MS, as it has been shown, at least for PLGA nanoparticles, that they can escape from vesicular compartments into the cytoplasm $[44,36]$. It is theoretically possible that maturation of phagosomes via TLR ligands accelerates such a release mechanism or the protection of antigen from lysosomal degradation [44].

The yield of $9 \%$ of SIINFEKL-specific CTL after a single vaccination is very high and compares favorably to approaches using chemical conjugates of ovalbumin and CpG oligonucleotides [25], vaccination with virus-like particles [45], DC-based vaccination [46], or DNA vaccination [47,48]. Compared to the high numbers of SIINFEKL/H-2K ${ }^{\mathrm{b}}$ tetramer positive CTL (Fig. 5), the number of specific CTL that could be stimulated with the SIINFEKL peptide to produce IFN- $\gamma$ in vitro was only in the order of $2-3 \%$ (Fig. 4). Such a difference between these two detection systems, which has also been observed by other laboratories, may be due to the short re-stimulation time of $5 \mathrm{~h}$ because a longer period of re-stimulation led to increased numbers of IFN- $\gamma$ producing cells (data not shown). In addition to IFN- $\gamma$ production, the CTL induced by vaccination with PLGA-MS were biologically active in that they lysed SIINFEKL-pulsed target cells in vivo and in vitro (Fig. 6) and protected mice from the infection with rVV-OVA (Fig. 7). While this manuscript was under review, a study by Heit et al. also reported that strong CTL responses to ovalbumin could be elicited with PLGA microspheres containing both OVA and CPG oligonucleotide [49]. In that study protection from lethal infection with Listeria monocytogenes and growth of pre-established B16 melanoma could be demonstrated. Heit et al. produced their PLGA-MS by the solvent/evaporation technique while we performed the pharmaceutically more applicable spray-drying method. The two papers together show that irrespective of the production method, PLGA-MS are excellent tools for CTL vaccination. Another study that appeared while our paper was in revision showed that the immunization of mice with PLGA-MS containing recombinant prion protein and $\mathrm{CpG}$ oligonucleotide was able to induce antibodies, T helper-, and CTL responses to the prion protein [50]. Interestingly, also for this antigen, the inclusion of antigen and adjuvant in the same microspheres yielded better stimulation of $\mathrm{CD}^{+}$and $\mathrm{CD}^{+} \mathrm{T}$ cells than immunization with a mixture of MS containing the single components indicating that the paradigm of coencapsulation is not only valid for vaccination with one model antigen.

The potency of PLGA-MS as CTL vaccines has probably several reasons. First, they are degraded over a period of about 30 days during which the encapsulated antigen and adjuvant are most likely protected from degradation by proteases, RNAses, and DNAses. This persistence gives DC a better chance to acquire the antigen. Second, PLGA-MS can be manufactured by spray drying to obtain particle diameters in the range of $1-5 \mu \mathrm{m}$ which is appropriate for uptake by DC [28]. Uptake of PLGA-MS by murine BMDC and human monocyte-derived $D C$ has indeed been shown to be very efficient and fast [15]. Third, loading of DC with PLGA-MS does not negatively affect their pivotal biological properties like cytokine secretion, $T$ cell stimulation, and migration [15]. Fourth, PLGA-MS have been shown to achieve an excellent efficiency of cross-presentation by DC $[12,51]$ which may be linked to their particulate nature [52] and the escape of PLGA-MS from phagosomes into the cytoplasm $[53,36]$. Here we add a further advantage to this list, namely that PLGA-MS can be reproducibly manufactured to contain both protein antigens and nucleic acids as adjuvants which can stimulate their cognate TLR after phagocytosis of MS. The coencapsulation of several adjuvants, which trigger different TLR pathways, may further enhance the immune response [54]. Although it remains to be shown in vitro by fluorescence microscopy if phagosomes do indeed mature specifically and provide the cell surface with peptide/class I complexes if their cargo contains TLR ligands, our in vivo data is consistent with this mechanism. The importance of coencapsulating adjuvant and antigen for achieving better CTL responses, however, is a new parameter that is evident from our results and which will help to further optimize immunotherapies aiming at the eradication of malignant or virus infected cells.

\section{Acknowledgements}

We thank Antje Heit and Hermann Wagner for scientific advice and stimulating discussions, Ying Waeckerle-Men for initial help with MS production, and Michael Basler for sharing his experience with CTL assays. This work was supported by grant no. 10-2156 (MG) of Deutsche Krebshilfe e.V.

\section{References}

[1] Steinman RM, Hawiger D, Nussenzweig MC. Tolerogenic dendritic cells. Annu Rev Immunol 2003;21:685-711.

[2] Akira S. TLR signaling. Curr Top Microbiol Immunol 2006;311:1-16.

[3] Bevan MJ. Cross-priming for a secondary cytotoxic response to minor $\mathrm{H}$ antigens with $\mathrm{H}-2$ congenic cells which do not crossreact in cytotoxic assay. J Exp Med 1976;143(5):1283-8.

[4] Basta S, Alatery A. The cross-priming pathway: a portrait of an intricate immune system. Scand J Immunol 2007;65(4): 311-9.

[5] Rock KL, Shen L. Cross-presentation: underlying mechanisms and role in immune surveillance. Immunol Rev 2005;207:166-83.

[6] Redmond WL, Sherman LA. Peripheral tolerance of CD8 T lymphocytes. Immunity 2005;22(3):275-84.

[7] Blander JM, Medzhitov R. Regulation of phagosome maturation by signals from toll-like receptors. Science 2004;304(5673):1014-8.

[8] Blander JM, Medzhitov R. Toll-dependent selection of microbial antigens for presentation by dendritic cells. Nature 2006;440(7085):808-12. 
[9] Yarovinsky F, Kanzler H, Hieny S, Coffman RL, Sher A. Toll-like receptor recognition regulates immunodominance in an antimicrobial CD4+ T cell response. Immunity 2006;25(4):655-64.

[10] Gander B. Trends in particulate antigen and DNA delivery systems for vaccines. Adv Drug Deliv Rev 2005;57(3):321-3.

[11] Thomasin C, Corradin G, Men Y, Merkle HP, Gander B. Tetanus toxoid and synthetic malaria antigen containing poly(lactide)/poly(lactide-co-glycolide) microspheres: importance of polymer degradation and antigen release for immune response. J Control Release 1996;41:131-45.

[12] WaeckerleMen Y, Allmen EU, Gander B, Scandella E, Schlosser $\mathrm{E}$, Schmidtke $\mathrm{G}$, et al. Encapsulation of proteins and peptides into biodegradable poly (D,L-lactide-co-glycolide) microspheres prolongs and enhances antigen presentation by human dendritic cells. Vaccine 2006;24(11):1847-57.

[13] Partidos CD, Vohra P, Jones D, Farrar G, Steward MW. CTL responses induced by a single immunization with peptide encapsulated in biodegradable microparticles. J Immunol Methods 1997;206(1-2):143-51.

[14] Otten G, Schaefer M, Greer C, Calderon-Cacia M, Coit $D$, Kazzaz J, et al. Induction of broad and potent antihuman immunodeficiency virus immune responses in rhesus macaques by priming with a DNA vaccine and boosting with protein-adsorbed polylactide coglycolide microparticles. J Virol 2003;77(10):6087-92.

[15] Waeckerle-Men Y, Scandella E, Allmen EU, Ludewig B, Gillessen $S$, Merkle HP, et al. Phenotype and functional analysis of human monocyte-derived dendritic cells loaded with biodegradable poly(lactide-co-glycolide) microspheres for immunotherapy. J Immunol Method 2004;287(1/2):109-24.

[16] Waeckerle-Men Y, Gander B, Groettrup M. Delivery of tumor antigens to dendritic cells using biodegradable microspheres. Methods Mol Med 2005;109:35-46.

[17] Schiemann M, Busch V, Linkemann K, Huster KM, Busch $\mathrm{DH}$. Differences in maintenance of $\mathrm{CD}^{+}$and $\mathrm{CD} 4^{+}$bacteriaspecific effector memory $\mathrm{T}$ cell populations. Eur J Immunol 2003;33(10):2875-85.

[18] Barber DL, Wherry EJ, Ahmed R. Cutting edge: rapid in vivo killing by memory CD8 T cells. J Immunol 2003;171(1):27-31.

[19] Schwarz K, van den Broek M, Kostka S, Kraft R, Soza A, Schmidtke $G$, et al. Overexpression of the proteasome subunits LMP2, LMP7, and MECL-1 but not PA28 $\alpha / \beta$ enhances the presentation of an immunodominant lymphocytic choriomeningitis virus T cell epitope. J Immunol 2000;165(2):76878.

[20] Zhu G, Mallery SR, Schwendeman SP. Stabilization of proteins encapsulated in injectable poly (lactide-co-glycolide). Nat Biotechnol 2000;18(1):52-7.

[21] Miconnet I, Koenig S, Speiser D, Krieg A, Guillaume P, Cerottini JC, et al. CpG are efficient adjuvants for specific CTL induction against tumor antigen-derived peptide. J Immunol 2002;168(3):1212-8.

[22] Binder D, Kündig TM. Antiviral protection by $\mathrm{CD} 8^{+}$versus $\mathrm{CD} 4^{+}$ $\mathrm{T}$ cells. CD8 ${ }^{+} \mathrm{T}$ cells correlating with cytotoxic activity in vitro are more efficient in antivaccina virus protection than CD4dependent IL. J Immunol 1991;146(12):4301-7.

[23] Ashkar AA, Bauer S, Mitchell WJ, Vieira J, Rosenthal KL. Local delivery of $\mathrm{CpG}$ oligonucleotides induces rapid changes in the genital mucosa and inhibits replication, but not entry, of herpes simplex virus type 2. J Virol 2003;77(16):8948-56.

[24] Cho HJ, Takabayashi K, Cheng PM, Nguyen MD, Corr M, Tuck S, et al. Immunostimulatory DNA-based vaccines induce cytotoxic lymphocyte activity by a T-helper cell-independent mechanism. Nat Biotechnol 2000;18(5):509-14.

[25] Heit A, Schmitz F, O'Keeffe M, Staib C, Busch DH, Wagner H, et al. Protective CD8 T cell immunity triggered by $\mathrm{CpG}$-protein conjugates competes with the efficacy of live vaccines. J Immunol 2005;174(7):4373-80.
[26] Schirmbeck R, Riedl P, Zurbriggen R, Akira S, Reimann J. Antigenic epitopes fused to cationic peptide bound to oligonucleotides facilitate toll-like receptor 9-dependent, but $\mathrm{CD}^{+}$ $\mathrm{T}$ cell help-independent, priming of $\mathrm{CD}^{+} \mathrm{T}$ cells. $\mathrm{J}$ Immunol 2003;171(10):5198-207.

[27] Wille-Reece U, Flynn BJ, Lore K, Koup RA, Kedl RM, Mattapallil JJ, et al. HIV Gag protein conjugated to a toll-like receptor 7/8 agonist improves the magnitude and quality of Th1 and CD8 ${ }^{+} \mathrm{T}$ cell responses in nonhuman primates. Proc Natl Acad Sci USA 2005;102(42):15190-4.

[28] Shen Z, Reznikoff G, Dranoff G, Rock KL. Cloned dendritic cells can present exogenous antigens on both MHC class I and class II molecules. J Immunol 1997;158(6):2723-30.

[29] Storni T, Ruedl C, Schwarz K, Schwendener RA, Renner WA, Bachmann MF. Nonmethylated CG motifs packaged into virus-like particles induce protective cytotoxic $T$ cell responses in the absence of systemic side effects. J Immunol 2004;172(3):1777-85.

[30] Walter E, Dreher D, Kok M, Thiele L, Kiama SG, Gehr P, et al. Hydrophilic poly(DL-lactide-co-glycolide) microspheres for the delivery of DNA to human-derived macrophages and dendritic cells. J Control Release 2001;76(1-2):149-68.

[31] Hunter SK, Andracki ME, Krieg AM. Biodegradable microspheres containing group B Streptococcus vaccine: immune response in mice. Am J Obstet Gynecol 2001;185(5):1174-9.

[32] Singh M, Kazzaz J, Chesko J, Soenawan E, Ugozzoli M, Giuliani $M$, et al. Anionic microparticles are a potent delivery system for recombinant antigens from Neisseria meningitidis serotype B. J Pharm Sci 2004;93(2):273-82.

[33] Kazzaz J, Singh M, Ugozzoli M, Chesko J, Soenawan E, O'Hagan DT. Encapsulation of the immune potentiators MPL and RC529 in PLG microparticles enhances their potency. J Control Release 2006;110(3):566-73.

[34] Westwood A, Elvin SJ, Healey GD, Williamson ED, Eyles JE. Immunological responses after immunization of mice with microparticles containing antigen and single stranded RNA (polyuridylic acid). Vaccine 2006;24(11):1736-43.

[35] Men Y, Audran R, Thomasin C, Eberl G, Demotz S, Merkle $\mathrm{HP}$, et al. MHC class I- and class II-restricted processing and presentation of microencapsulated antigens. Vaccine 1999;17(9/10):1047-56.

[36] Shen H, Ackerman AL, Cody V, Giodini A, Hinson ER, Cresswell $P$, et al. Enhanced and prolonged cross-presentation following endosomal escape of exogenous antigens encapsulated in biodegradable nanoparticles. Immunology 2006;117(1):78-88.

[37] Guermonprez P, Amigorena S. Pathways for antigen cross presentation. Springer Semin Immunopathol 2005;26(3):25771.

[38] Guermonprez P, Saveanu L, Kleijmeer M, Davoust J, vanEndert P, Amigorena S. ER-phagosome fusion defines an MHC class I cross-presentation compartment in dendritic cells. Nature 2003;425(6956):397-402.

[39] Houde M, Bertholet S, Gagnon E, Brunet S, Goyette G, Laplante A, et al. Phagosomes are competent organelles for antigen cross-presentation. Nature 2003;425(6956):402-6.

[40] Ackerman AL, Kyritsis C, Tampe R, Cresswell P. Early phagosomes in dendritic cells form a cellular compartment sufficient for cross presentation of exogenous antigens. Proc Nat Acad Sci USA 2003;100(22):12889-94.

[41] Stober D, Trobonjaca Z, Reimann J, Schirmbeck R. Dendritic cells pulsed with exogenous hepatitis B surface antigen particles efficiently present epitopes to MHC class I-restricted cytotoxic T cells. Eur J Immunol 2002;32(4):1099-108.

[42] Kovacsovics-Bankowski M, Rock KL. A phagosome-to-cytosol pathway for exogenous antigens presented on MHC class I molecules. Science 1995;267(5195):243-6.

[43] Rodriguez A, Regnault A, Kleijmeer M, Ricciardi Castagnoli P, Amigorena S. Selective transport of internalized antigens to 
the cytosol for MHC class I presentation in dendritic cells. Nat Cell Biol 1999;1(6):362-8.

[44] Savina A, Jancic C, Hugues S, Guermonprez P, Vargas P, Cruz Moura I, et al. NOX2 controls phagosomal pH to regulate antigen processing during crosspresentation by dendritic cells. Cell 2006;126(1):205-18.

[45] Schwarz K, Meijerink E, Speiser DE, Tissot AC, Cielens I, Renhof R, et al. Efficient homologous prime-boost strategies for $\mathrm{T}$ cell vaccination based on virus-like particles. Eur J Immunol 2005;35(3):816-21.

[46] Ludewig B, Oehen S, Barchiesi F, Schwendener RA, Hengartner $\mathrm{H}$, Zinkernagel RM. Protective antiviral cytotoxic T cell memory is most efficiently maintained by restimulation via dendritic cells. J Immunol 1999;163(4):1839-44.

[47] Rodriguez F, Harkins S, Slifka MK, Whitton JL. Immunodominance in virus-induced CD8(+) T-cell responses is dramatically modified by DNA immunization and is regulated by gamma interferon. J Virol 2002;76(9):4251-9.

[48] Öhlschläger P, Osen W, Dell K, Faath S, Garcea RL, Jochmus I, et al. Human papillomavirus type $16 \mathrm{~L} 1$ capsomeres induce $\mathrm{L} 1$ specific T lymphocytes and tumor regression in C57BL/6 mice. J Virol 2003;77:4635-45.

[49] Heit A, Schmitz F, Haas T, Busch DH, Wagner H. Antigen coencapsulated with adjuvants efficiently drive protective $T$ cell immunity. Eur J Immunol 2007;37(8):2063-74.
[50] Kaiser-Schulz G, Heit A, Quintanilla-Martinez L, Hammerschmidt $F$, Hess $S$, Jennen $L$, et al. Polylactide-coglycolide microspheres coencapsulating recombinant tandem prion protein with $\mathrm{CpG}$ oligonucleotide break self-tolerance to prion protein in wild-type mice and induce CD4 and CD8 T cell responses. J Immunol 2007;179(5):2797807.

[51] Audran R, Peter K, Dannull J, Men Y, Groettrup M, Gander B, et al. Encapsulation of peptides prolongs their presentation to cytotoxic $T$ cells by antigen presenting cells in vitro. Vaccine 2003;21(11/12):1250-5.

[52] Kovacsovics-Bankowski M, Clark K, Benacerraf B, Rock KL. Efficient major histocompatibility complex class I presentation of exogenous antigen upon phagocytosis by macrophages. Proc Natl Acad Sci USA 1993;90(11):4942-6.

[53] Panyam J, Zhou WZ, Prabha S, Sahoo SK, Labhasetwar V. Rapid endo-lysosomal escape of poly(DL-lactide-co-glycolide) nanoparticles: implications for drug and gene delivery. FASEB J 2002;16(10):1217-26.

[54] Napolitani G, Rinaldi A, Bertoni F, Sallusto F, Lanzavecchia A. Selected toll-like receptor agonist combinations synergistically trigger a $\mathrm{T}$ helper 1-polarizing program in dendritic cells. Nat Immunol 2005;6(8):749-50. 